\section{GC-MS studies to map mechanistic aspects of photolytic decomposition of pesticides}

\author{
Attila Kiss - Diána Virág \\ EGERFOOD Regional Academic Knowledge Centre \\ Eszterházy Károly College, Eger \\ attkiss@ektf.hu
}

\begin{abstract}
SUMMARY
Transformation of pesticides in the environment is a highly complex process affected by different factors. Both biological and physical-chemical factors may play a role in the degradation, whose ratio depends on the actual environmental conditions.

Our study aims to reveal specific details of photolytic degradation of pesticides as important soil contaminants. Significance of these studies is enhanced by the fact that pesticide decomposition may contribute to soil degradation, and have harmful biological effects by degrading to toxic products. The toxicity of the examined pesticides is well known, however very little information is available regarding their natural degradation processes, the quality, structure and biological impact of the degradation products.

The photolytic degradation of frequently applied pesticides of distinctive types (acetochlor - acetanilide, simazine - triazine, chlorpyrifos - organophosphate, carbendazim - benzimidazole) was investigated. A special, immerseable UV-light source was applied in order to carry out photodegradation. The degradation processes were followed by thin layer chromatography (TLC) and mass spectrometry coupled with gas chromatography (GC/MS). EI mass spectrometry was used to identify the degradation species.

Each of the studied pesticides underwent photolytic decomposition, and the detailed mechanism of photolytic transformation was established. At least four degradation species were detected and identified in each case. Loss of alkyl, alkyloxy, amino-alkyl and chloro groups might be regarded as typical decomposition patterns. Deamination occurred at the last stage of decomposition.
\end{abstract}

Keywords: pesticide, photodecomposition, GC/MS technique, degradation products, degradation mechanism

\section{INTRODUCTION}

Making a survey of pesticide degradation occurring in the environment is of high interest as both basic compounds and decomposition products as soil or plant residues might have harmful character.

Photochemical degradation of pesticides is the breakdown of pesticides by light, particularly sunlight. Photochemical degradation of pesticides can be applied for the decontamination of natural water or contaminated soils (Aaron et al., 2001; Coly et al., 1994).

A comparative study between fragmentation processes taking place in mass spectrometry using an electron ionization source and photodegradation processes has been carried out for atrazine, simazine and trietazine (Tremolada et al., 1993). Simazine showed the lowest tendency to fragmentation, and atrazine the highest. The same kind of fragmentations were observed for the three compounds: $\mathrm{C}-\mathrm{N}$ bond cleavage in the lateral chains, $\mathrm{C}-\mathrm{Cl}$ bond scission and heteroatomic ring cleavage.

Pelizzetti et al. (1990) studied the $\mathrm{TiO}_{2}$ photocatalyzed degradation of atrazine, simazine, trietazine, prometon and prometryn by simulated sunlight in aqueous solution, using a Xe lamp. All the herbicides were rapidly degraded. Full mineralization was not observed. Different intermediates have been identified, cyanuric acid being the common final photoproduct of all herbicides.

Triazine-derivatives are considered to be the representatives of pesticides of the most wide-spread practical application, therefore it is of crucial importance to reveal their fate in the environment. Among ways of transformation photodegradation can be regarded as one of the most significant factors (Vidal et al., 1999). It was shown that some triazine herbicides undergo photodegradation to form deaminated derivatives of the original compound (Mansour et al., 1993).

The mechanism of the most frequent triazine pesticide, atrazine degradation was investigated in aqueous phase by sonolysis at $20 \mathrm{kHz}$, ozonation, photolysis at $254 \mathrm{~nm}$ and photocatalysis in the presence of $\mathrm{TiO} 2$, either separately or simultaneously (Bianchi et al., 2006). Ozonation and photocatalysis induced atrazine dealkylation, followed by slower dechlorination, while direct photolysis at $254 \mathrm{~nm}$ promoted very efficient dechlorination.

Brekken and Brezonik (1998) studied the reaction between acetochlor and HO-, assuming that the primary source of $\mathrm{HO}$ is nitrate photolysis. According to their experimental data the direct photolysis would be much slower than HO-mediated degradation.

In case of acetochlor serious efforts have been made in order to identify biodegradation products of the pesticide, however no specific reaction pathways have been mapped (Coleman et al., 2000; Zheng et al., 2003).

The photodegradation of chlorpyrifos by simulated sunlight in water /methanol (2-4\%) has been studied by Barcelo et al. (1993) 3,5,6-trichloro2-pyridinol was identified as the only degradation product of chlorpyrifos during its photodecomposition. A method, based on the technique of solid-phase microextraction, was developed to determine the rate of reaction of chlorpyrifos with $\mathrm{HO}$ radicals in the gas phase at high temperatures during its photodecomposition (Hebert et al., 2000). 
The visible-light-promoted photodegradation of carbendazim was studied in water or water-methanol solution, in the presence of air and as a photosensitizer synthetic xanthene dye Rose Bengal $(\mathrm{RB})$ or the natural pigment riboflavin (Rf) (Escalada et al., 2006). It was stated that the degradation process depends on experimental conditions such as the concentrations of dissolved oxygen and carbendazim. The aqueous photodegradation of carbendazim was studied by Ibarz et al. (2000) at various $\mathrm{pH}$ values, using the radiation supplied by a mercury lamp emitting between 250 and $750 \mathrm{~nm}$. It was established that the rate of photodegradation increased with $\mathrm{pH}$ and oxygen concentrations.

To sum up the abovementioned information we may claim that in case of photodegradation numerous studies have been performed especially concerning striazines. However with the exception of atrazine detailed reaction mechanisms of the concerned pesticides have not been revealed. In some cases specific degradation products were detected without the aim of mapping the entire mechanism of photodegradation. Thus our work contributes to a more extensive and comprehensive knowledge on pesticide photodecomposition with regard to both reaction mechanism and chemical feature of degradation products. Mechanism of photolytic degradation is mapped by GC-MS identification of degradation products.

\section{MATERIALS AND METHODS}

The four pesticides examined, which have diverse chemical structures and action mechanisms, are acetochlor (acetanilide herbicide), simazine (triazine herbicide), chlorpyrifos (organophosphate insecticide), and carbendazim (benzimidazole fungicide). The chemical properties of the pesticides are summarized in Table 1. The examined pesticides (higher than 99\% HPLC purity) and other applied chemicals were purchased from Aldrich.

Table 1

Chemical structure and name of the studied pesticides

\begin{tabular}{|c|c|c|c|c|}
\hline & Acetochlor & Simazine & Chlorpyripfos & Carbendazim \\
\hline $\begin{array}{l}\text { Chemical } \\
\text { structure }\end{array}$ & 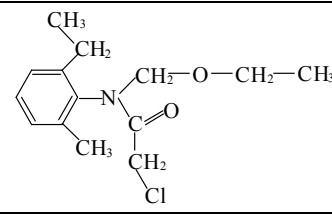 & $\mathrm{H}_{3} \mathrm{C}-\mathrm{CH}_{2}-\stackrel{\mathrm{N}}{\mathrm{N}}$ & $\mathrm{Cl}$ & \\
\hline $\begin{array}{l}\text { Chemical } \\
\text { name }\end{array}$ & $\begin{array}{l}\text { 2-chloro-N-(ethoxymethyl)- } \\
\text { N-(2-ethyl-6-methylphenyl) } \\
\text { acetamide }\end{array}$ & $\begin{array}{l}\text { 6-chloro-N2, N4-diethyl- } \\
\text { 1,3,5-triazine-2,4-diamine }\end{array}$ & $\begin{array}{c}\text { diethoxy-sulfanylidene-(3,5,6- } \\
\text { trichloropyridin-2-yl) oxy- } \\
\text { phosphorane }\end{array}$ & $\begin{array}{l}\text { methyl 3H- } \\
\text { benzoimidazol-2- } \\
\text { ylaminoformate }\end{array}$ \\
\hline
\end{tabular}

Solutions of $1(\mathrm{~m} / \mathrm{m}) \%$ were produced from the pure herbicides. Into these solutions the specific UV light source was immersed emitting constantly light of $254 \mathrm{~nm}$ wavelength. The light source was a low pressure mercury-vapour lamp of $15 \mathrm{~W}$ output manufactured by Millipore company.

Thin layer chromatography was performed on precoated Merck 5554 Kieselgel $60 \mathrm{~F}_{254}$ foils using a 9:1 chloroform-methanol developing system. The degradation process was followed by TLC and GC. Following the completion of photodegradation, the reaction mixtures were extracted with $3 \times 20 \mathrm{ml}$ dichloromethane and vacuum rotary evaporated. The pesticides and the obtained products were identified by using GC/MS technique. The structure identifications based on the interpretation of the fragmentation pathways.

The GC separations and the mass spectrometric measurements were performed by using a GC-GC/MS QP-2010S Shimadzu under the next measuring conditions: column: HP-5MS $(30 \mathrm{~m} \times 0.25$ $\mathrm{mm} \times 0.25 \mathrm{um})$, carrier gas: He $(1 \mathrm{ml} / \mathrm{min})$, detector: GC/MS QP-2010S, ionization mode: EI $(70 \mathrm{eV})$, interface temperature: $230{ }^{\circ} \mathrm{C}$, ionsource temperature: $200{ }^{\circ} \mathrm{C}$, inject volume: $1 \mu \mathrm{l}$. The heating parameters were the follows: simazine: $110{ }^{\circ} \mathrm{C}$ (hold: $\left.0 \mathrm{~min}\right) \rightarrow$ $240{ }^{\circ} \mathrm{C}\left(15{ }^{\circ} \mathrm{C} / \mathrm{min}\right)$ (hold: $\left.0 \mathrm{~min}\right) \rightarrow 290{ }^{\circ} \mathrm{C}$
(35 ${ }^{\circ} \mathrm{C} / \mathrm{min}$ ) (hold: $0.5 \mathrm{~min}$ ); chlorpyrifos: $150{ }^{\circ} \mathrm{C}$ (hold: $0 \mathrm{~min}) \rightarrow 290{ }^{\circ} \mathrm{C}\left(20{ }^{\circ} \mathrm{C} / \mathrm{min}\right)$ (hold: $\left.3 \mathrm{~min}\right)$; acetochlor: $80{ }^{\circ} \mathrm{C}$ (hold: $\left.0 \mathrm{~min}\right) \rightarrow 280{ }^{\circ} \mathrm{C}\left(15^{\circ} \mathrm{C} / \mathrm{min}\right)$ (hold: $0 \mathrm{~min}$ ); carbendazim: $90{ }^{\circ} \mathrm{C}$ (hold: $\left.1 \mathrm{~min}\right) \rightarrow$ $200{ }^{\circ} \mathrm{C}\left(10{ }^{\circ} \mathrm{C} / \mathrm{min}\right)$ (hold: $\left.0 \mathrm{~min}\right) \rightarrow 280{ }^{\circ} \mathrm{C}$ $\left(20{ }^{\circ} \mathrm{C} / \mathrm{min}\right.$ ) (hold: $0 \mathrm{~min}$.).

\section{RESULTS AND DISCUSSION}

In case of the photodegradation of acetochlor there are alternative reaction pathways according to our findings (Figure 1). Several degradation products could be detected subsequent to some hours of irradiation, as it could be observed in Figure 2 and 3. Major steps of photodecomposition are as follows: cleavage of ester-bond of N-ethoxy-methyl group, breaking off the chloro- and the hydroxyl-groups, thus the formation of 2-ethyl-6-methyl-N-methylaniline. This last degradation product could be formed from the basic compound in a direct way as well. Alternatively the cleavage of chloro-, methyland ethoxy-groups of the basic compound and the production of formanilid-derivatives (Table 2). Cleavage of methyl-, ethyl and amino-groups produced toluene. Toluene is the only end-product having confirmed impeding biological effects. 
Figure 1: Proposed degradation mechanism of acetochlor

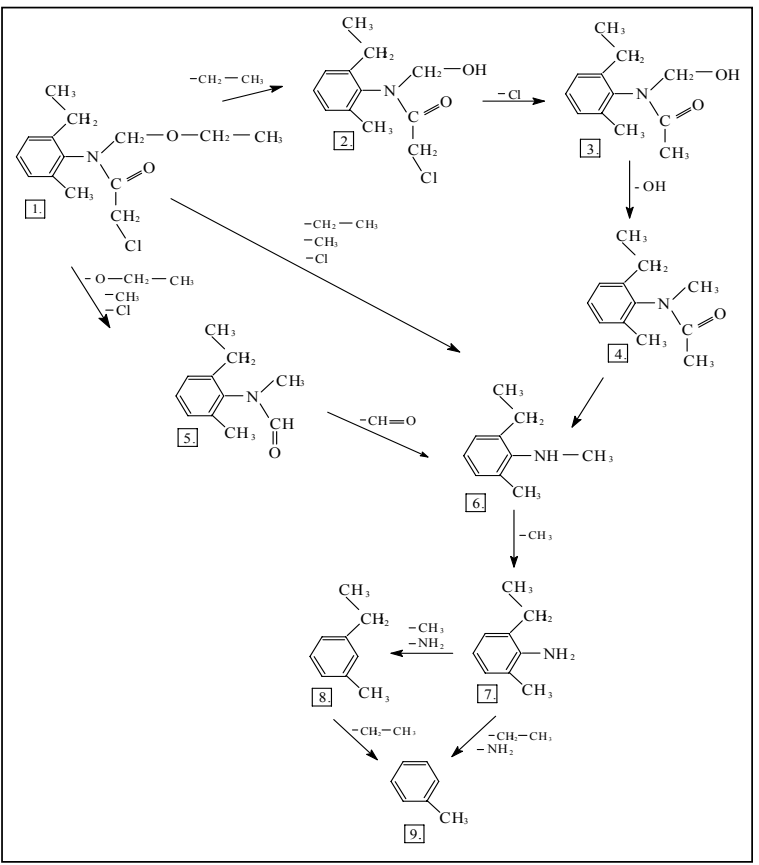

Figure 2: The GC-chromatogram of acetochlor and its degradation product after 3 hours of UV-irradiation

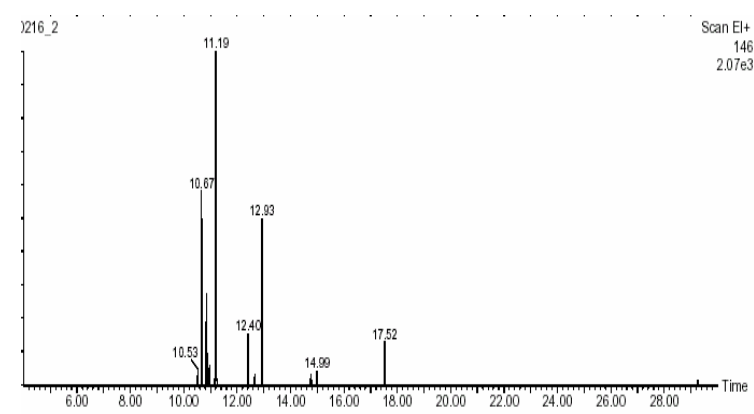

Three main degradation products we detected were also determined by other studies aiming at modeling biodegradation of acetochlor (Coleman et al., 2000; Zheng et al., 2003), but so far the total degradation mechanism of acetochlor has not been revealed. The determination of all 9 degradation products and mapping the entire degradation mechanism by our experiments contributes to the accurate understanding of acetochlor's environmental behaviour.

Figure 3: The mass-spectrums of the basic compound and the main degradation products of acetochlor
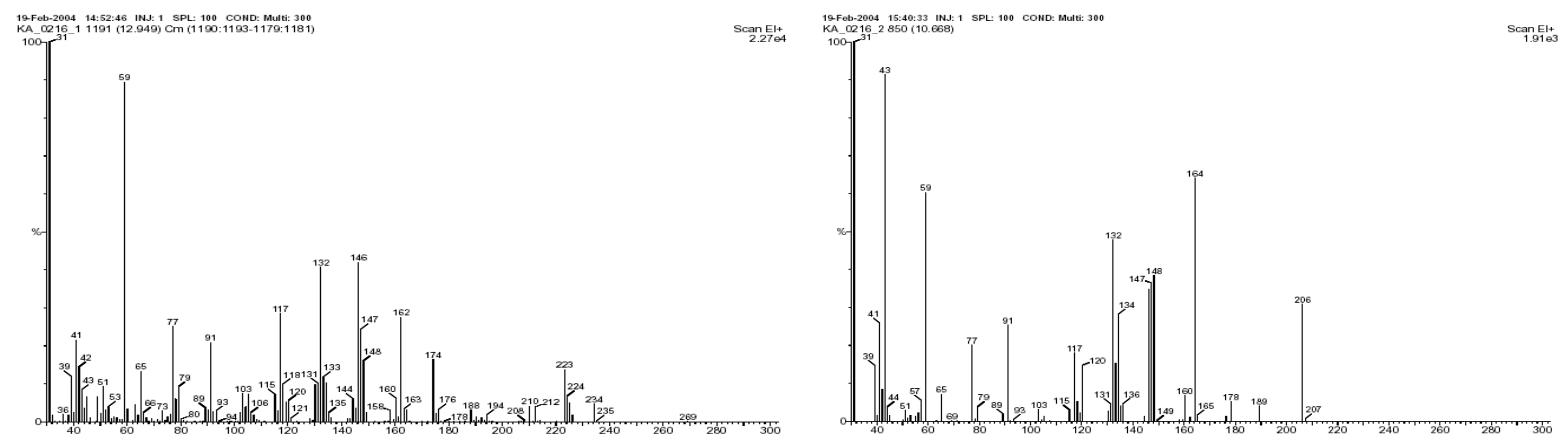

Table 2

Products of photolytic degradation of acetochlor, their molecular mass and retention time at GC-chromatogram

\begin{tabular}{|c|c|c|c|}
\hline & Name of compound & Molecular mass (g/mol) & Retention time \\
\hline 1. & 2-chloro-N-(ethoxymethyl)-N-(2-ethyl-6-methyl-phenyl)-acetamide & 269.5 & 12.950 \\
\hline 2. & 2-chloro-N-hydroximethyl-N-(2-ethyl-6-methyl-phenyl)-acetamide & 241.5 & 17.543 \\
\hline 3. & N-hydroximethyl-N-(2-ethyl-6-methylphenyl)-acetamide & 207.0 & 10.668 \\
\hline 4. & N-methyl-N-(2-ethyl-6-methylphenyl)-acetamide & 191.0 & 11.195 \\
\hline 5. & N-methyl-N-(2-ethyl-6-methylphenyl)-formamide & 176.0 & 10.468 \\
\hline 6. & 2-ethyl-6-methyl-N-methyl-aniline & 149.0 & 12.408 \\
\hline 7. & 2-ethyl-6-methyl-aniline & 135.0 & 10.530 \\
\hline 8. & 3-ethyl-toluene & 120.0 & 14.990 \\
\hline 9. & toluene & 92.0 & 10.855 \\
\hline
\end{tabular}

The degradation of simazine effected by UV-photons can take place via two parallel reaction pathways. Major steps of the photodecomposition were found to be as follows: cleavage of a chlorogroup and substitution of $\mathrm{Cl}$ to $\mathrm{OH}$-group, loss of methyl and ethyl groups, and scissoring of OH-group. The most stabile product 2,4-di(ethylamino)-1,3,5-triazine was, the symmetrical 2,4-diamino-1,3,5-triazine is obtained as the end-product of degradation (Figure 4).

Efforts aiming at investigating the photolythic degradation of simazine have only established so far the fact of the degradation as well as the factors influencing it. Hence the identification of all degradation products (Table 3) and revealing the complete decomposition mechanism signify new findings. 


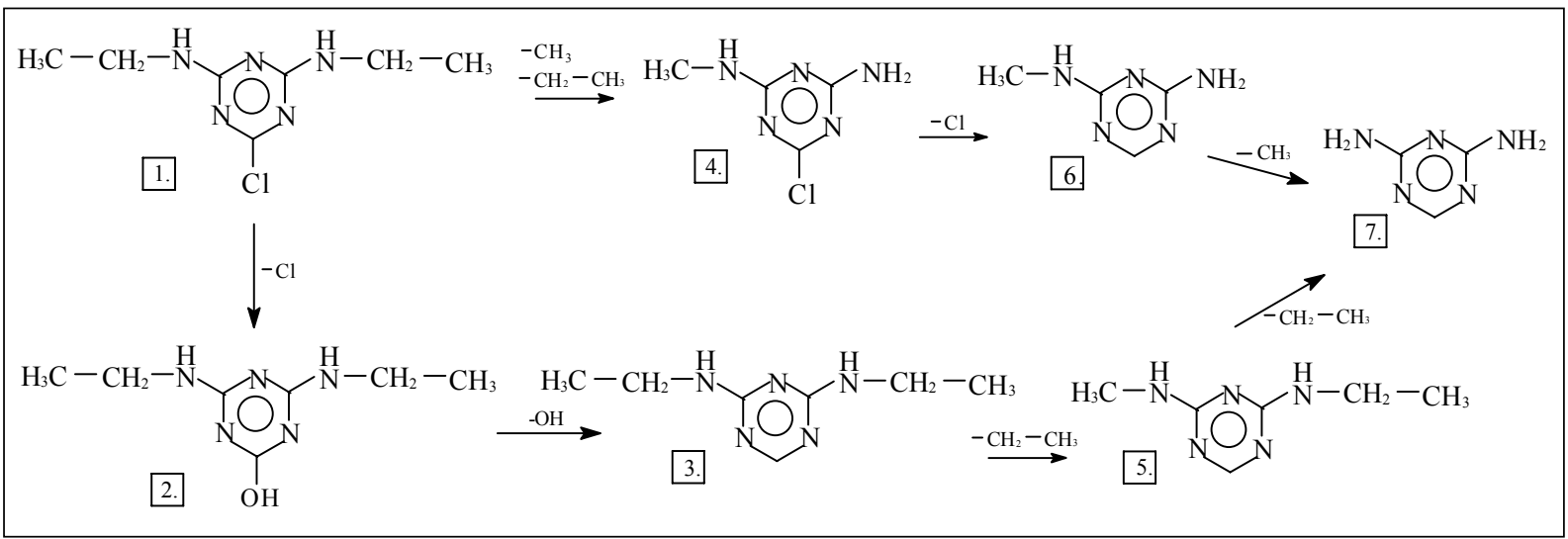

Products of photolytic degradation of simazine, their molecular mass and retention-time in the GC-chromatogram

\begin{tabular}{|c|c|c|}
\hline Name of compound & $\begin{array}{c}\text { Molecular } \\
\text { mass (g/mol) }\end{array}$ & $\begin{array}{c}\text { Retention } \\
\text { time }\end{array}$ \\
\hline $\begin{array}{l}\text { 1. 2,6-di(ethylamino)-4-chloro- } \\
\text { 1,3,5-triazine }\end{array}$ & 201.7 & 7.374 \\
\hline $\begin{array}{l}\text { 2. 2,4-di(ethylamino)-hydroxy- } \\
\text { 1,3,5-triazine }\end{array}$ & 183.2 & 8.061 \\
\hline $\begin{array}{l}\text { 3. 2,4-di(ethylamino)-1,3,5- } \\
\text { triazine }\end{array}$ & 167.2 & 6.481 \\
\hline $\begin{array}{l}\text { 4. 2-amino-4-chloro-6- } \\
\text { methylamino-1,3,5-triazine }\end{array}$ & 159.7 & 5.327 \\
\hline $\begin{array}{l}\text { 5. 2-ethylamino-4-methylamino- } \\
\text { 1,3,5-triazine }\end{array}$ & 139.2 & 3.774 \\
\hline $\begin{array}{l}\text { 6. 2-amino-4-methylamino- } \\
\text { 1,3,5-triazine }\end{array}$ & 125.2 & 5.321 \\
\hline 7. 2,4-diamino-1,3,5-triazine & 111.2 & 4.914 \\
\hline
\end{tabular}

Figure 5: The GC-chromatogram of chlorpyrifos and its degradation products after 5 hour UV-irradiation

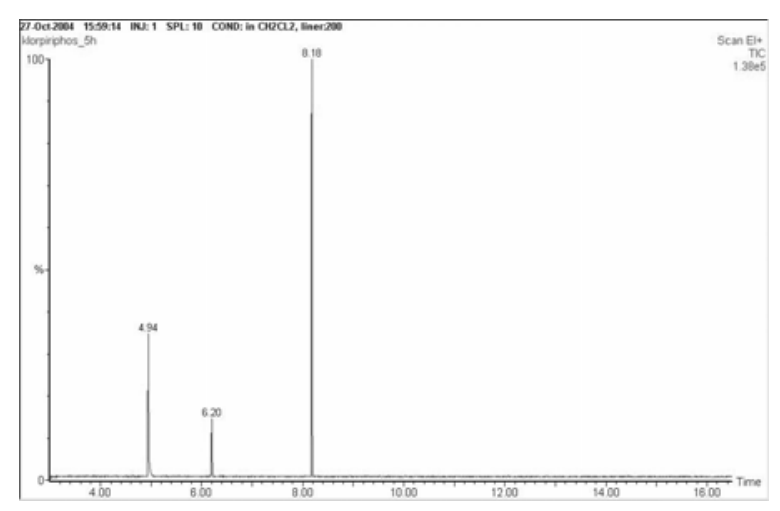

The loss of the other ethyl-group results in forming (5-chloro-2-pyridil)-dihydrogenethiophosphate as an end-product (Table 4). Based on the GC-chromatograms it can be established that after 16 hours of irradiation the chlorpyrifos suffers a total photodegradation and only the end-product of the decomposition might be observed in the reaction sphere. The biological degradation of chlorpyrifos resulted in different metabolites than that justified by our investigations (Coleman et al., 2000).

The photodegradation of chlorpyrifos can occur in two reaction patterns (Figure 6). It might be initiated by the cleavage of either a chloro-group or an ethyl-group. Breaking away of an other chlorogroup leads to the formation of ethyl-(5-chloro-2pyridil)-hydrogene-thiophosphate. The existence of this metabolite is confirmed by the five-hour massspectrums (Figure 5, 6).

Table 4

Products of photolytic degradation of chlorpyrifos, their molecular mass and retention-time in the GC-chromatograms

\begin{tabular}{|c|l|r|c|}
\hline & \multicolumn{1}{|c|}{ Name of compound } & \multicolumn{1}{|c|}{$\begin{array}{c}\text { Molecular } \\
\text { mass (g/mol) }\end{array}$} & $\begin{array}{c}\text { Retention } \\
\text { time }\end{array}$ \\
\hline 1. & $\begin{array}{l}\text { diethyl-(3,5,6-trichloro-2- } \\
\text { pyridil)-thiophosphate }\end{array}$ & 350.6 & 8.180 \\
\hline 2. & $\begin{array}{l}\text { ethyl-(3,5,6-trichloro-2- } \\
\text { pyridil)-hydrogene- } \\
\text { thiophosphate }\end{array}$ & 323.0 & 5.861 \\
\hline 3. & $\begin{array}{l}\text { diethyl-(3,5-dichloro-2- } \\
\text { pyridil)-thiophosphate }\end{array}$ & 316.5 & 5.710 \\
\hline 4. & $\begin{array}{l}\text { ethyl-(3,5-dichloro-2- } \\
\text { pyridil)-hydrogene- } \\
\text { thiophosphate }\end{array}$ & 288.5 & 6.661 \\
\hline 5. & $\begin{array}{l}\text { ethyl-(5-chloro-2-pyridil)- } \\
\text { hydrogene-thiophosphate }\end{array}$ & 254.0 & 6.201 \\
\hline 6. & $\begin{array}{l}\text { (5-chloro-2-pyridil)- } \\
\text { dihydrogene-thiophosphate }\end{array}$ & 225.5 & 4.940 \\
\hline
\end{tabular}


Figure 6: The mass-spectrums of the main degradation products of chlorpyrifos

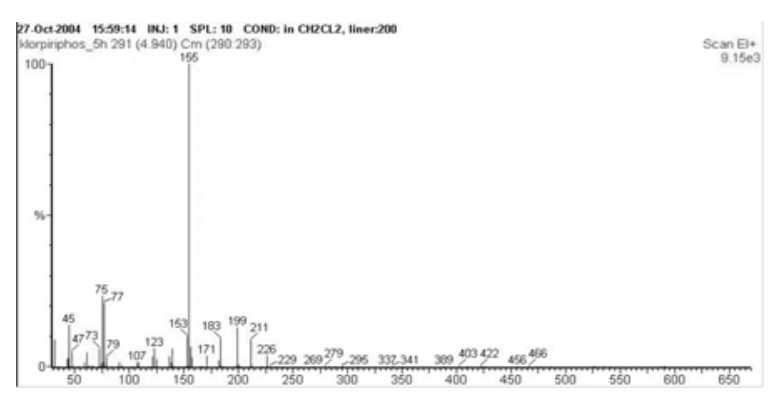

The first step of the degradation of carbendazim was the loss of O-methyl group and the formation of $\mathrm{N}$-(benzimidazole-2-il)-carbamic-acid.

This metabolite showed small stability, and after the cleavage of hydroxil- and the carbonyl group it transformed into 2-amino-benzimidazole.

The 2-amino-benzimidazole seemed to be more stable, as several hours of UV-irradiation was needed to degrade it to benzimidazole. This metabolite was the most persistent compound against light because 6-hours of UV-irradiation was needed for the imidazole-ring to be opened up and for the 2-methylamino-aniline to be formed. After this, the cleavage of $\mathrm{N}$-methyl bond led to formation of the end-product of the photodegradation: 1,2-diaminobenzene (Table 5).

Figure 7: The GC-chromatogram of carbendazim and its degradation products after 8 hours of UV-irradiation

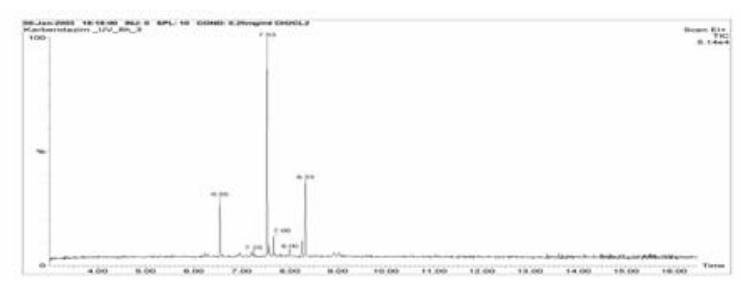

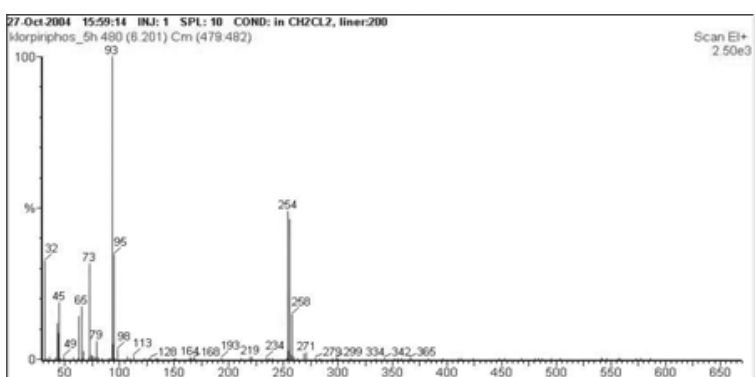

GC-chromatogram and mass-spectrums of carbendazim and its degradation products (including the stable 2-amino-benzimidazole) subsequent to 8 hours of irradiation are demonstrated in Figures 7 and 8.

Besides the identification of five degradation products, we also established the degradation mechanism of carbendazim. Our results are new as according to the literary other degradation product than 2-amino-benzimidazole has not been identified so far.

Table 5

Degradation products of photolytic decomposition of carbendazim, their molecular mass and retention-time in the GC-chromatograms

\begin{tabular}{|c|l|r|r|}
\hline & \multicolumn{1}{|c|}{ Name of compound } & \multicolumn{1}{|c|}{$\begin{array}{c}\text { Molecular } \\
\text { mass (g/mol) }\end{array}$} & $\begin{array}{c}\text { Retention } \\
\text { time }\end{array}$ \\
\hline 1. & $\begin{array}{l}\text { methyl-(N-benzimidazole-2- } \\
\text { ilcarbamate) }\end{array}$ & 191 & 7.530 \\
\hline 2. & $\begin{array}{l}\text { N-(benzimidazole-2-il)- } \\
\text { carbamic-acide }\end{array}$ & 177 & 6.561 \\
\hline 3. & $\begin{array}{l}\text { N-(benzimidazole-2-il)- } \\
\text { carbamate }\end{array}$ & 161 & 8.328 \\
\hline 4. & 2-amino-benzimidazole & 133 & 8.280 \\
\hline 5. & Benzimidazole & 118 & 7.662 \\
\hline 6. & 2-methyl-amino-aniline & 122 & 8.003 \\
\hline 7. & 1,2-diaminobenzene & 108 & 7.248 \\
\hline
\end{tabular}

Figure 8: The mass-spectrums of the two main degradation products

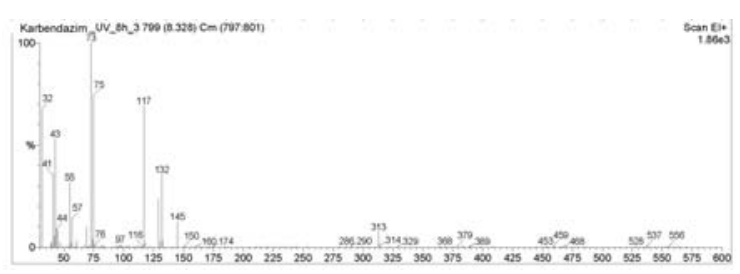

\section{CONCLUSIONS}

Phototransformation of pesticides has to be regarded as a key factor in their environmental behaviour. Each of the four different examined pesticides underwent photolytic decomposition, and the detailed mechanism of photolytic transformation was established. GC-MS technique proved to be a suitable method for detection and identification of formed degradation products. At least five distinctive degradation species were detected in each case, and

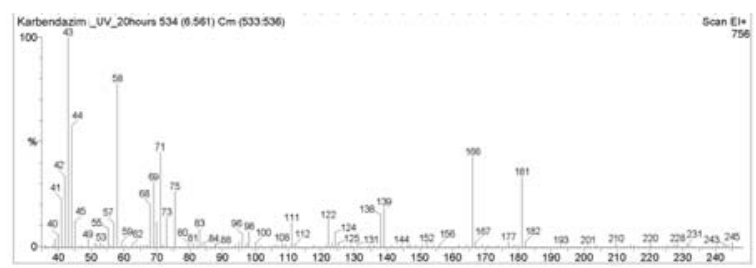

parallel pathways of photodecomposition could be observed for two pesticides.

Typical initial decomposition patterns were found to be cleavage of ester-bond, loss of e alkyl-groups, breaking up of chloro-groups. Following degradation pathways were established as follows: cleavage of ester-bonds, destruction of $\mathrm{N}$-alkoxy, $\mathrm{N}$-alkyl group, and hydroxyl-groups. Deamination and rig opening occurred at the last stage of decomposition. Possibly toxic degradation products have been observed as well. 
The research on revealing the exact reaction mechanisms of photolytic degradation of pesticides contributes not only to the proper understanding of environmental behaviour of pesticides, but also points out the possible environmental and biological risk factors by identifying possibly toxic degradation products (Virág et al., 2007).

\section{REFERENCES}

Aaron, J. J.-Oturan, M. A. (2001): New photochemical and electrochemical methods for the degradation of pesticides in aqueous media. Environmental applications.Turk. J. Chem. 25:509-520.

Barcelo, D.-Durand, G.-Bertrand, N. D. (1993): Photodegradation of the organophosphorus pesticides chlorpyrifos, fenamiphos and vamidothion in water. Toxicol. Environ. Chem. 38. 183199.

Bianchi, C. L.-Pirola, C.-Ragaini, V.-Selli, E. (2006): Mechanism and efficiency of atrazine degradation under combined oxidation processes. Applied Catalysis B: Environmental 64. 131-138.

Brekken, J. F.-Brezonik, P. L. (1998): Indirect photolysis of acetochlor: Rate constant of a nitrate-mediated hydroxyl radical reaction. Chemosphere 36. 2699-2704.

Coleman, S.-Linderman, R.-Hodgson, E.-Rose, L. (2000): Comparative metabolism of chloroacetamide herbicides and selected metabolites in human and rat liver microsomes. R. Environ. Health Perspect. 108. 1151-1157.

Coly, A.-Aaron, J. J. (1994): Fluorimetric determination of aromatic persticides in technical formulations. Effects of solvent and of ultraviolet photolysis. Talanta 41. 1475.

Escalada, J. P.-Pajares, A.-Gianotti, J.-Massad, W. A.-Bertolotti, S.-Amat-Guerri, F.-García, N. A. (2006): Dye-sensitized photodegradation of the fungicide carbendazim and related benzimidazoles. Chemospere 65. 2. 237-244.
Hebert, V. R.-Hoonhout, C.-Miller, G. C. (2000): Use of stable tracer studies to evaluate pesticide photolysis at elevated temperatures. J. Agric. Food Chem. 48. 1916-1921.

Ibarz, A.-Panadés, R.-Esplugas, S. (2000): Photodecomposition of carbendazim in aqueous solutions. Water Research 34. 11. 2951-2954.

Mansour, M. (ed.) (1993): Fate and Prediction of Enviromental Chemicals in Soils, Plants and Aquatic Systems. Lewis, Boca Raton, Ann Arbor, USA

Pelizzetti, E.-Maurino, V.-Minero, C.-Carlin, V.-Pramauro, E.Zerbinat, O.-Tosato, M. L. (1990): Environ. Sci. Technol. 24. 1559-1565.

Tremolada, P.-Davoli, E.-Guardo, A. D.-Fanelli, R.-Calamari, D.Biagini, G. (ed.) (1993): Proceedings of the 9th Symposium on Pesticide Chemistry, Lucca, Italy, 509-518.

Vidal, A.-Dinya, Z.-Mogyoródi, F. (1999): Photocatalytic Degradation of Thiocarbamate Herbicide Active Ingredients in Water. Applied Catalysis B, Environmental 21. 259.

Virág, D.-Naár, Z.-Kiss, A. (2007): Microbial toxicity of pesticide derivatives produced with UV-photodegradation. Bullentin of Environmental Contamination and Toxicology. 2007 September; 79(3): 356-9.

Zheng, H. H.-Ye, C. M. (2003): Photodegradation of acetochlor in water and UV photoproducts identified by mass spectrometry. Journal of Environmental Sciences-China 15 (6) 783-790. 